\title{
Peran dan Kontribusi Ilmuwan Muslim dalam Pembelajaran Matematika
}

\author{
Dini Palupi Putri \\ Institut Agama Islam Negeri (IAIN) Curup \\ dinigusnadi@gmail.com
}

\begin{tabular}{l}
\hline \hline Article Info \\
\hline Article history: \\
Received April $20^{\text {th }}, 2019$ \\
Revised April $26^{\text {th }}, 2019$ \\
Accepted May $1^{\text {st }}, 2019$ \\
\hline
\end{tabular}

Keywords:

Roles;

Contributions;

Muslim Scientists;

Mathematics Learning

The life that is lived now and in the future cannot be separated from the role of history in the past. Mathematics learning plays an important role in everyday life, often we find problems in everyday life can be solved with mathematical concepts. In learning mathematics, mathematical scientists contribute greatly to the learning of mathematics and mathematical concepts. It cannot be denied, in the golden age of Islam many Muslim scientists sprang up, including mathematical scientists. Muslim mathematicians who were very famous, one of them was al-Khawarizmi. The branch of science in mathematics put forward by alKhawarizmi is Algebra. Algebra is very much used in the life of the current global era. Algebra is found in many daily activities, such as buying and selling, Mawaris knowledge, and so on. al- Khawarizmi is also an inventor of zeros and the originator of the concept of algorithms. In addition, this paper will discuss the contribution of scientist Ibn al- Haytham to the concept of absolute value, al-Biruni towards the concept of "The Broken Chord" theorem, al- Khayyami on the concept of geometry. The mathematical concepts found by scientists are what we use a lot today to solve problems used in everyday life.

Kata Kunci:

Peran;

Kontribusi;

Ilmuwan Muslim;

Pembelajaran Matematika

\section{Abstrak}

Kehidupan yang dijalani sekarang dan akan datang tidak terlepas dari peran sejarah di masa lalu. Pembelajaran matematika sangat berperan penting dalam kehidupan sehari-hari, sering kita temukan permasalahan-permasalahan di kehidupan sehari-hari 
64 | Putri: Peran dan Kontribusi Ilmuwan Muslim dalam Pembelajaran Matematika

dapat diselesaikan dengan konsep-konsep matematika. Dalam pembelajaran matematika, ilmuwan matematika sangat berkontribusi dalam pembelajaran matematika dan konsep-konsep matematika. Tidak dapat dipungkiri, pada zaman keemasan islam banyak bermunculan ilmuwan-ilmuwan muslim, termasuk ilmuwan matematika. Ilmuwan matematika muslim yang sangat terkemuka salah satunya al-Khawarizmi. Cabang ilmu dalam matematika yang dikemukakan al-Khawarizmi adalah Aljabar. Aljabar sangat banyak digunakan dalam kehidupan era global saat ini. Aljabar banyak ditemukan dalam aktifitas sehari-hari, seperti jual beli, ilmu mawaris, dan lain sebagainya. al-Khawarizmi juga seorang penemu angka nol dan penggagas konsep algoritma. Selain itu dalam tulisan ini akan dibahas tentang kontribusi ilmuwan Ibn al-Haytham terhadap konsep nilai mutlak, al-Biruni terhadap konsep teorema "The Broken Chord", al-Khayyami terhadap konsep geometri. Konsep-konsep matematika yang ditemukan oleh ilmuwan inilah yang banyak kita manfaatkan saat ini untuk menyelesaikan masalah yang digunakan dalam kehidupan sehari-hari.

\section{PENDAHULUAN}

Matematika merupakan ilmu universal yang mendasari perkembangan teknologi modern. Matematika mempunyai peran penting dalam berbagai disiplin ilmu sehingga memajukan daya pikir manusia. Pada kehidupan sehari-hari, sering kita temukan aplikasi dari perhitungan matematika. Misalnya, ketika berbelanja di warung, kita akan menghitung uang hasil belanja. Kegiatan menghitung atau menjumlah adalah salah satu konsep dalam matematika. Seorang ilmuwan sering melakukan perhitungan matematika untuk mendukung teori yang ditemukannya. Dalam bidang ekonomi, matematika juga memiliki peran yang tidak kalah penting. Demikian halnya di bidang fisika, kimia, biologi, dan sosial, peranan matematika sangatlah besar. Oleh karena itu, matematika dianggap sebagai ibu dari segala ilmu pengetahuan.

Matematika sering digunakan dalam perhitungan berbagai kegiatan dalam kehidupan sehari-hari. Ketika berbelanja, belajar, atau bermain, 
proses hitung menghitung tentu kita lakukan. Adapun proses hitung menghitung merupakan salah satu cabang yang dipelajari dalam matematika. Matematika memiliki peranan yang penting dalam ilmu pengetahuan. Adapun matematika adalah pembelajaran konsep-konsep mengenai bilangan, bentuk, dan jumlah. Penjumlahan, pengurangan, pembagian dan perkalian adalah bagian dari cabang ilmu matematika. Konsep-konsep matematika yang kita pelajari dan kita manfaatkan dalam kehidupan sehari-hari pada saat ini tidak terlepas dari peran dan kontribusi dari ilmuwan terdahulu yang menemukan dan mengembangkan ilmu matematika.

Kondisi yang sering dijumpai di lapangan yaitu pada proses pembelajaran matematika masih ditemukan kesulitan dari peserta didik, seperti kesulitan dalam operasi aljabar, mengkomunikasikan masalah matematika ke dalam gambar, bagan dan grafik, menyelesaikan permasalahan matematika yang diberikan pendidik, dan banyak lagi kesulitan-kesulitan yang ditemukan dalam pembelajaran matematika, baik itu pada proses penyampaian konsep-konsep matematika maupun ketika peserta didik dihadapkan pada soal-soal penyelesaian masalah. Jika hal seperti ini tidak diatasi, maka sikap positif peserta didik dalam pembelajaran sulit untuk dimunculkan dan dikembangkan.

Ketakutan dan kesulitan peserta didik dalam pembelajaran matematika dikarenakan abstraksi pembelajaran matematika sulit dipecahkan oleh peserta didik, Metode mengajar yang tidak tepat, pembelajaran matematika yang membutuhkan pikiran dan analisa yang tinggi seharusnya dimulai dari pemberian motivasi atau mendahului kegiatan pembelajaran dengan bercerita agar peserta didik menjadi rileks. Agar pembelajaran matematika lebih menarik pemusatan peserta didik, di awal pembelajaran pendidik bisa menceritakan para penemu konsep matematika terdahulu dan mengaitkan dengan materi yang akan dipelajari sehingga memunculkan sikap positif peserta didik terhadap konsepkonsep matematika.

Panasuk dan Horton dalam (Wahyu \& Mahfudy, 2016) mengungkapkan bahwa persepsi guru matematika terhadap penerapan 
sejarah matematika dengan tiga asumsi kunci yaitu: (1) sejarah matematika memberikan landasan pemahaman yang mendalam tentang evolusi konsep matematika; (2) memahami kenapa dan bagaimana konsep matematika dikembangkan selama bertahun-tahun dengan kerja keras; (3) belajar sejarah matematika bisa meningkatkan minat dan mengembangkan sikap positif siswa terhadap matematika. Perubahanperubahan konsep matematika dari yang kompleks menjadi lebih sederhana atau sebaliknya dapat kita ketahui melalui sejarah matematika. Konsep-konsep matematika yang banyak berperan di kehidupan sekarang ini ditemukan dengan kerja keras, dengan mengetahui alur penemuan konsep-konsep matematika yang ditemukan maka sikap positif peserta didik terhadap matematika dapat dikembangkan.

Ilmuwan-ilmuwan matematika banyak disinggung di buku teks pembelajaran atau di sumber bacaan lainnya. Jika disebut nama ilmuwan, seperti al-Khawarizmi, peserta didik mengenal nama tersebut. Namun, ketika ditanya apa kontribusi yang disumbangkan oleh al-Khawarizmi terhadap konsep matematika, sebagian peserta didik tidak tahu dengan kontribusi yang disumbangkan oleh al-Khawarizmi. Kondisi seperti ini semestinya harus diperbaiki, dalam pembelajaran perlu disiapkan waktu beberapa menit untuk menyampaikan kontribusi ilmuwan matematika terdahulu dan bagaimana peranan konsep-konsep matematika yang telah ditemukan.

Ilmu matematika telah ada sejak ribuan tahun yang lalu. Mereka menggunakan angka (bilangan) untuk menyatakan banyak atau sedikitnya suatu obyek. Selain itu, angka digunakan untuk menjumlahkan berat, ringan, panjang, pendek, atau lurus suatu obyek. Sekitar 1400 tahun yang lalu, orang-orang India telah menggunakan sistem angka. Selanjutnya bangsa Arab mengembangkan sistem angka tersebut menjadi seperti yang kita kenal sekarang.

Perjalanan sejarah dan peradaban Islam terdahulu sangatlah berpengaruh terhadap kemajuan ilmu pengetahuan saat ini. Zaman keemasan peradaban Islam ditunjukkan pada kondisi dimana para ilmuwan-ilmuwan muslim berkumpul dalam satu kekhalifahan Arab, 
Persia, dan Spanyol. Adanya ilmuwan-ilmuwan muslim di masa keemasan dahulu sangat disayangkan jika kita semua tidak mengenal dengan baik penemuan-penemuan dan kontribusi mereka terhadap konsep-konsep matematika yang kita pelajari sekarang serta bagaimana konsep-konsep matematika yang ditemukan ilmuwan-ilmuwan digunakan pada masa modern yang kita jalani saat ini.

\section{METODE PENELITIAN}

Artikel ini ditulis dengan menggunakan metode Library Research (Studi Pustaka), dimana penulis mengumpulkan referensi-referensi terkait ilmuwan-ilmuwan muslim dalam bidang matematika serta peran dan kontribusinya dalam pembelajaran matematika. Referensi tersebut berupa Jurnal Online, Proceeding, Buku. Ketiga referensi tersebut dibaca dan dipahami untuk mendapatkan informasi apa saja peran dan kontribusi ilmuwan muslim dalam pembelajaran matematika. Informasi yang diperoleh dianalisis sesuai dengan konteks kontribusi dan peran ilmuwan muslim dalam pembelajaran matematika. Hasil bacaan dan analisis bertujuan agar pembaca mengetahui apa-apa saja kontribusi ilmuwan muslim dalam pembelajaran matematika, dan bagaimana peranan hasil kontribusi ilmuwan muslim dalam pembelajaran matematika yang kita pelajari saat ini.

\section{HASIL PENELITIAN DAN PEMBAHASAN Muhammad ibn Musa al-Khawarizmi}

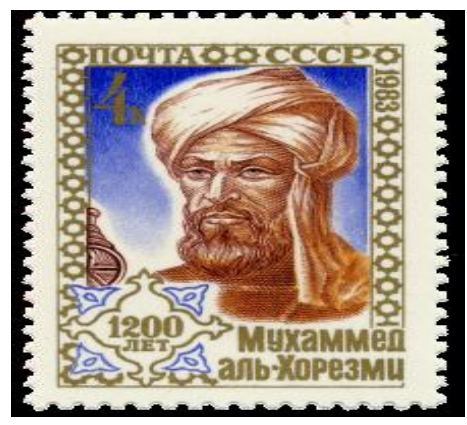

Gambar 1. Muhammad ibn Musa al-Khawarizmi 
Pemakaian angka dalam matematika memiliki arti yang sangat penting. Proses hitung-menghitung menjadi mudah dengan ditemukannya angka. Perkembangan ilmu matematika pun kian pesat. Ada seorang ahli matematika yang berperan penting dalam mengembangkan ilmu matematika. Ahli matematika tersebut bernama Ibnu Musa alKhawarizmi (780-850 M) yang berasal dari Persia. Ia menemukan teknik penyelesaian masalah-masalah yang dapat ditunjukkan dalam bentuk matematika. Teknik tersebut dinamakan aljabar (Murtiningsih, 2011). Selain seorang ahli matematika, al-Khawarizmi menekuni bidang astronomi. Karena kepandaian dan kecerdasan yang dimiliknya, alKhawarizmi bergabung pada lembaga Dar al-Hukama, yaitu sebuah lembaga penelitian pengembangan ilmu pengetahuan yang didirikan pada masa Bani Abbasiyah oleh Khilafah Harun ar-Rasyid.

Al-Khawarizmi menulis tiga buah buku yang berhubungan dengan matematika. Salah satu bukunya yang terkenal berjudul Hisab Al Jabr Wa'i Muqabalah (Ilmu Tentang Persamaan) yang diterbitkan $820 \mathrm{M}$. Buku itu membahas pengurangan dan penjumlahan yang merupakan hal pokok dalam ilmu matematika. Peranan aljabar dalam penyelesaian masalah yang dapat ditunjukkan dalam bentuk matematika sangatlah penting. Penyelesaian terhadap suatu masalah dapat dilakukan dengan membuat simbol. Dalam matematika kita dituntut untuk menyelesaikan berbagai persoalan. Sebagai contoh, suatu bilangan yang tidak diketahui nilainya dapat disimbolkan oleh sebuah huruf, misalnya a, b, atau c. Huruf tersebut mewakili bilangan yang tidak diketahui dan disebut dengan variabel. Adapun variabel-variabel tersebut dapat dibentuk menjadi persamaan aljabar. Sebagai contoh persamaan $2 y+4 x=12$.

Aljabar yang dibahas dalam buku hisab Al-Jabr Wa'l Muqabala berisi 800 contoh persoalan. Contoh-contoh tersebut dijadikan pedoman untuk menyelesaikan berbagai persoalan matematika dalam kehidupan sehari-hari. Sebagai contoh, masalah tempat tinggal, warisan, hukum, pembagian harta dan perdagangan. Adapun kata aljabar yang menjadi cabang ilmu matematika yang penting diambil dari nama salah satu buku al-Khawarizmi. 
Aljabar terus berkembang seiring dengan perjalanan waktu. AlKhawarizmi berjasa besar sebagai peletak dasar ilmu aljabar. Dapat dikatakan pula, al-Khawarizmi penemu ilmu tersebut sehingga sering disebut Bapak Aljabar.

Aljabar dapat diartikan pula dengan membuat bilangan negatif menjadi positif. Caranya dengan memindahkan bilangan negatif ke sisi persamaan lain sehingga bilangan tersebut menjadi positif. Tambahan lagi, buku Hisab Al-Jabr Wa'i Muqabala terlah diterjemahkan ke dalam berbagai bahasa. Akibatnya, aljabar makin tersebar luas dan mudah dipahami. Selain itu, nama al-Khawarizmi digunakan sebagai salah satu istilah dalam matematika, yaitu algoritm (algoritma). Adapun algoritma adalah langkah-langkah yang teratur untuk memecahkan masalah matematika. Dalam bahasa Arab aljabar dikenal dengan al-jabr. Sementara itu, dalam bahasa inggris dikenal dengan sebutan Algebra.

Buku Hisab Al-Jabr Wa'l Muqabah telah diterjemahkan dalam bahasa latin pada abad pertengahan. Buku itu juga digunakan untuk rujukan utama sejarah matematika. Awalnya, para ilmuwan muslim mewarisi ilmu matematika sebelum peradaban Yunani dan Hindu. Pada abad ke-8 hingga ke-15, ilmuwan muslim memberikan sumbangannya pada perkembangan ilmu matematika. Selanjutnya, matematika umumnya berasal dari Iran atau Irak.

Buku lainnya yang ditulis al-Khawarizmi berjudul Al-Jem Wa'l Tafraq bi Hisab al-Hind. Buku itu membahas penggunaan bilangan pada matematika untuk pertama kali. Bilangan tersebut berhubungan dengan operasi dasar matematika, penjumlahan, pengurangan, pembagian, dan perkalian. Akan tetapi, tetap mengakui bahwa karya ilmiah alKhawarizmi adalah dalam hal aljabar.

Al-Khawarizmi adalah salah satu ilmuwan matematika. Ia adalah ahli matematika. Ia adalah ahli matematika dan astronomi. Tiga buah buku telah ditulis dan kesemuanya berhubungan dengan matematika. Buku-buku itu dibuat sekitar tahun 830 M. Dalam bukunya, alKhawarizmi memperkenalkan cara melakukan penjumlahan bilangan akar kuadrat. Pengembangan ilmu geometri juga dilakukan al-Khawarizmi. 
Adapun geometri adalah cabang ilmu matematika yang menerangkan sifat-sifat garis, sudut, bidang dan ruang.

Teori-teori tentang bilangan rasional, irrasional dan geometri diterangkan dalam aljabar. Bilangan rasional adalah bilangan bulat atau hasil bagi bilangan bulat. Adapun bilangan irrasional adalah bilangan yang tidak dapat dinyatakan dengan bilangan pecahan. Teori dalam aljabar benar-benar baru dan berbeda dengan teori matematika sebelumnya. Aljabar dijadikan pedoman bagi pengembangan teori matematika selanjutnya. Hal penting dalam alajabar adalah pengembangan eksakta lainnya dapat dimungkinkan karena adanya aljabar.

Al-Khwarizmi banyak menggunakan aljabar dalam menggambarkan konsep geometri. Banyak bukti yang menunjukkan alKhawarizmi menghadirkan kembali angka-angka sederhana dan akar panjang garis segmen. Berbagai macam akar dan nomor mewakili area persegi panjang. Istilah persegi panjang dan hasilnya mewakili area persegi panjang. Istilah matematika yang populer seperti "completing square" penghitungan kubus atau "mengkuadratkan polinomial" berasal dari karya al-Khawarizmi dengan menggunakan konsep geometris yang diekpresikan melalui aljabar (Muhtar, 2014, hal. 90).

Al-Khawarizmi dijuluki sebagai bapak aljabar karena tulisannya yang sangat berharga. Adapun nama al-khawarizmi diabadikan dengan istilah algorhytm (algoritma). Algoritma adalah prosedur sistematis dalam memecahkan masalah matematika dengan langkah-langkah sederhana. Diungkapkan (Anwar, 2017, hal. 19) dari al-Khawarizmi, kita belajar banyak hal, diantaranya:

a. Bagaimana beliau membuat algoritma, bagian penting dari ilmu matematika, yang kita gunakan hingga sekarang;

b. Bagaimana beliau memperkenalkan angka nol sebagai nilai tempat. Bayangkan kalau tidak ada angka nol, tentu perhitungan akan kacau, kita akan kesulitan menuliskan angka 100, 1000, 1.000 .000 dan seterusnya; 
c. Bagaimana beliau memperkuat hadist nabi secara matematis tentang konsep pernikahan. Kalau kita memilih jodoh karena agama, diberi nilai 1 , jodoh kita ternyata cantik maka ditambah nol menjadi 10 , jodoh kita juga kaya, ditambah nol, menjadi 100, jodoh kita juga keturunan hebat, maka nilai nya ditambah nol, menjadi 1000. Tapi kalau jodoh yang kita pilih bukan utamakan agama, maka celakalah kita, yang berarti kalau dalam matematika, seberapa banyakpun angka 0 kalau tidak ada 1 di depan maka tidak akan bernilai.

Dikemukakan (Aji, 2014, hal. 167) tujuh hal yang patut diketahui untuk menelaah karya besar al-Khawarizmi sebagai sumbangan yang cukup berarti bagi literasi matematika. Pertama adalah al-Khawarizmi memperkenalkan desimal atau persepuluhan yang banyak digunakan saat ini untuk operasi angka di belakang koma, sebagai angka pecahan. Sumbangan kedua, penggunaan variabel dan simbol-simbol. Ketiga adalah menemukan bilangan nol, sumbangan angka nol oleh alKhawarizmi mengubah kemajuan penemuan angka lewat angka romawi yang belum mengenal angka nol. Keempat, penemuan nilai simbol phi $(\pi)$, nilai ini menyatakan perbandingan keliling sebuah lingkaran yang dipakai sampai saat ini. Kelima al-Khawarizmi juga menyusun daftar logaritma. Keenam, metode aljabar, temuan ini digunakan untuk menghitung tinggi segitiga. Ketujuh, merumuskan penyelesaian persamaan kuadrat dengan konsep variabel, parameter, dan akar kuadrat.

Salah satu penemuan al-Khawarismi tentang konsep aljabar, peran aljabar dari yang sederhana sampai yang kompleks sering kita jumpai di kehidupan sehari-hari. Permasalahan yang sederhana yang bisa diselesaikan oleh konsep aljabar misalnya melakukan pembayaran transaksi jual beli. Contoh persoalan "Ibu membeli 5 kilogram telur dan 3 kilogram tepung terigu, jika harga 1 kilogram tepung terigu adalah 2 kali harga telur. Tentukan harga masing-masing telur dan tepung terigu?" untuk menyelesaikan persoalan tersebut, al-Khawarizmi menawarkan penyelesaian permasalahan dengan membuat simbol atau huruf untuk harga telur atau tepung terigu yang belum diketahui, huruf-huruf tersebut dinamakan variabel selanjutnya menyelesaikan permasalahan tersebut 
menggunakan persamaan aljabar. Permasalahan dalam kehidupan seharihari yang kompleks yang bisa diselesaikan dengan aljabar, misalnya pembagian harta warisan. Dan masih banyak lagi permasalahanpermasalahan dalam kehidupan sehari-hari yang bisa kita selesaikan dengan konsep aljabar.

\section{Ibn al- Haytham, Abu Ali al-Hasan Ibn al- Hasan (965 - 1039)}

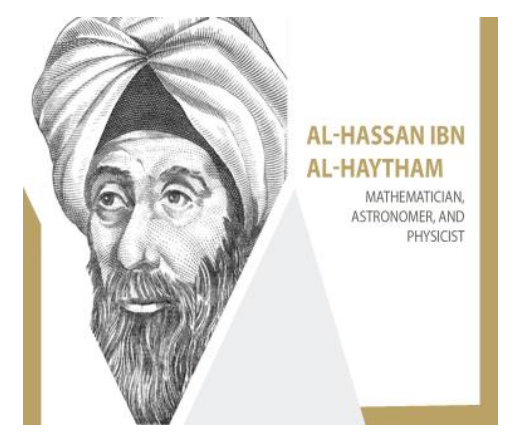

\section{Gambar 2. Ibn al- Haytham}

Ibn al-Haytham dilahirkan di Basra Irak. Di dunia barat dia lebih dikenal dengan nama Alhazen. Ia seorang fisikawan muslim terkemuka, ahli matematika, astronomi, filosofi, dan kedokteran. Salah satu kontribusinya dalam bidang matematika yaitu argumennya yang didasarkan pada pernyataan benar namun belum terbukti bahwa setiap nilai prima $\mathrm{P}$ membagi $(\mathrm{p}-1) !=1$. Ia juga memberikan metode dan prosedur guna membangun kotak magis dengan ukuran tertentu. Dalam tulisannya yang diterjemahkan oleh Rashed (1989), Ibn al-Haytham menganalisis nilai mutlak. Dalam tulisannya yang berjudul $A$ solid Arithmetic Problem, ia berhasil memecahkannya dengan bidang kerucut (Mohamed, 2004, hal. 210).

Beberapa tulisannya yang lain memberikan sumbangan besar bagi matematika terapan di masanya. Karya-karyanya mengenai aritmatika komersial, jangka untuk menggambar lingkaran, dan beberapa subjek lainnya yang berkaitan dengan pengukuran menunjukkan kepeduliannya akan kebutuhan praktis matematika. 
Analisis yang dilakukan Haytham terhadap nilai mutlak sangat berperan dalam pembelajaran matematika maupun penyelesaian permasalahan dalam kehidupan sehari-hari. Konsep nilai mutlak bertujuan untuk menemukan jangkauan dari nilai tertentu agar pernyataan yang diberikan bernilai benar. Contoh permasalahan yang dapat diselesaikan menggunakan nilai mutlak misalnya, jangkauan siswa dalam mengerjakan soal, jangkauan ketika melakukan kegiatan maju dan mundur dalam baris berbaris, jangkauan dari angka $\mathrm{km} / \mathrm{l}$ dari mobil, jangkauan kedalaman unuk menangkap ikan di laut dalam, jangkauan kepadatan lalu lintas, dan lain sebagainya.

\section{Al- Biruni, Abu Rayhan Muhammad Ibn Ahmad (973 - 1050)}

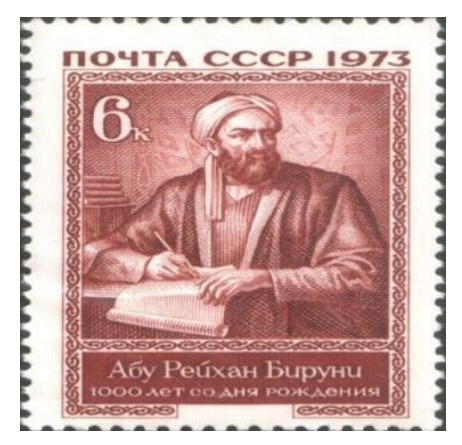

\section{Gambar 3. Al- Biruni}

Al-Biruni adalah seorang sarjana dari Afghanistan. Al-Biruni juga menguasai berbagai bidang pengetahuan dan keterampilan yaitu astronomi, matematika, geografi matematika, fisika, kimia, sejarah, agama, antropologi, kedokteran, dan puisi. Karya yang pernah ditulis alBiruni selama hidupnya diperkirakan berjumlah 138 buah. Al-Biruni menguasai bahasa Arab, Turki, Persia, Sansekerta, Syria dan beberapa dialek Indian dan Iran. Kontribusi Al-Biruni dalam literasi matematika adalah perumusan Sinus pada segitiga bidang $\frac{a}{\sin A}=\frac{b}{\sin B}=\frac{c}{\sin C}$, pembuktian Teorema The Broken Chord yaitu berkaitan dengan sudut keliling dalam sebuah lingkaran, penentuan arah kiblat dengan 
menggunakan metode gambar Al-Biruni sendiri menggunakan rumus cosinus segitiga bola, yaitu $\cos b=\cos a \cdot \cos c+\sin a \cdot \sin c \cdot B$

Teorema "The Broken Chord" (Mohamed, 2004)

Jika $\mathrm{AB}$ dan $\mathrm{BC}$ membentuk sebuah penghubung dua titik lingkaran yang terputus seperti gambar 1 , dan DE tegak lurus terhadap bagian yang lebih panjang yaitu $A B$ dari titik tengah busur $A B C$, maka $\mathrm{AE}=\mathrm{EB}+\mathrm{BC}$. Bukti: Buat $\mathrm{EZ}=\mathrm{EB}$ dan hubungkan DZ dan DB seperti Hubungkan busur $\mathrm{AD}$ dan $\mathrm{DC}$. Jika $\mathrm{AZ}=\mathrm{BC}$ dapat dibuktikan, maka dengan mudah mengikuti bahwa: $\mathrm{AE}=\mathrm{AZ}+\mathrm{ZE}$ dan $\mathrm{AE}=\mathrm{BC}+\mathrm{EB}$ atau $\mathrm{AE}=\mathrm{EB}+\mathrm{BC}$. Sehingga teorema terbukti.

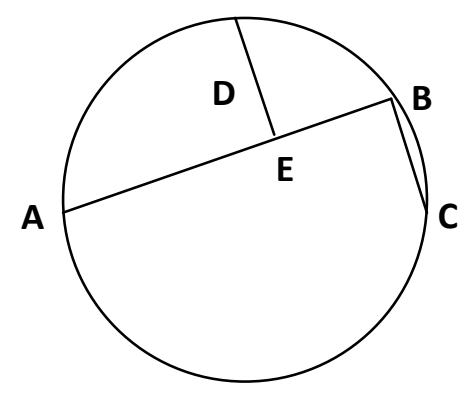

Gambar 4

Al- Biruni dalam bidang pemikirannya memberi manfaat yaitu dapat menghitung ketetapan waktu-waktu shalat sepanjang tahun, dapat menetapkan arah kiblat, dan lainnya. Dalam tulisannya (Anwar, 2017, hal. 20) mengungkapkan dari Al-Biruni kita belajar banyak hal, diantaranya: a. bagaimana kontribusi beliau cukup banyak dalam bidang matematika, memperkaya dan matematika sebagai sebuah ilmu; b. bagaimana beliau dengan ilmu matematika, mampu menentukan arah kiblat, sebagai pedoman kita dalam sholat; c.beliau juga ahli di bidang yang lain, seperti astronomi, ahli fisika, sejarahwan, filsuf, farmasi, dan lain sebagainya yang cukup langka untuk zaman sekarang ini.

\section{Al-Khayyami, Ghiyath al- Din Abu'l Fath Umar Ibn Ibrahim (1048 -} 1131) 
Omar Khayyam lahir di Nishabur salah satu wilayah Khurasan bagian dari daerah Iran pada tahun $439 \mathrm{H}$ atau $1048 \mathrm{M}$. Ayahnya bernama Ibrahim, salah satu pembuat tenda yang terkenal di daerah Nishabur. Omar Khayyam menghabiskan masa kecilnya di kota Balkh (sekarang utara Afghanistan). Omar Khayyam terkenal akan kejeniusan dan kepuitisannya, bukan hanya di negara-negara timur, akan tetapi juga terkenal di negara-negara barat. Omar Khayyam memberi banyak inspirasi bagi para sarjana-sarjana Timur dan Barat dalam bidang matematika, astronomi, sastra dan disiplin ilmu lainnya.

Omar Khayyam merupakan salah satu matematikawan muslim, yang bergerak dalam bidang matematika yang meliputi teori garis sejajar, teori perbandingan dan proporsi serta aljabar. Pembuktian yang dilakukan Omar Khayyam benar-benar membuka bab baru dalam kajian geometri yang mana memberikan jalan untuk penciptaan geometri non-Euclid. Di dalam buku II dan III karya Omar berhubungan dengan teori perbandingan dan proporsi. Defenisi Euclid tentang identitas dari dua perbandingan, a/b dan c/d yang dapat ditemukan kembali dalam istilah modern (Salmina, 2016).

Omar Khayyam, memiliki kontribusi besar dalam bidang matematika, terutama dalam bidang aljabar dan trigonometri. Ia matematikawan pertama yang menemukan metode umum penguraian akar-akar bilangan tingkat tinggi dalam aljabar, dan memperkenalkan solusi persamaan kubus. Omar Khayyam juga memecahkan persamaan pangkat tiga dan empat melalui kerucut-kerucut yang merupakan ilmu aljabar tertinggi dalam matematika modern.

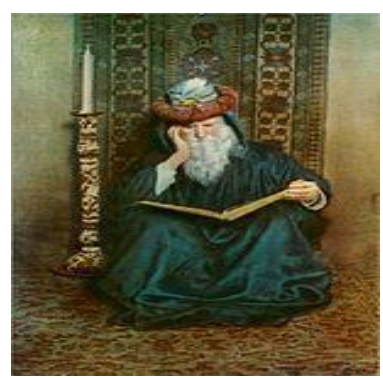

Gambar 5. Al-Khayammi 
Howard Eves (1980) dalam bukunya Great Moments in MathematicS (Before 1650) menulis bahwa : Omar Khayyam juga dicatat karena perbaikan kalendernya yang sangat akurat, perlakuan kritiknya terhadap dalil paralel Euclid yang memperlihatkan dia menjadi pelopor ide Saccheri yang akhirnya memimpin dalam penciptaan geometri nonEuclid, karena kontribusi aslinya untuk aljabar orang-orang Arab tempat dia melakukan pemecahan secara geometri, sejauh seperti akar-akar positif yang berhubungan, setiap tipe persamaan kubik.

\section{Abul Wafa Muhammad Ibnu Muhammad Ibnu Yahya Ibnu Ismail al Buzjani}

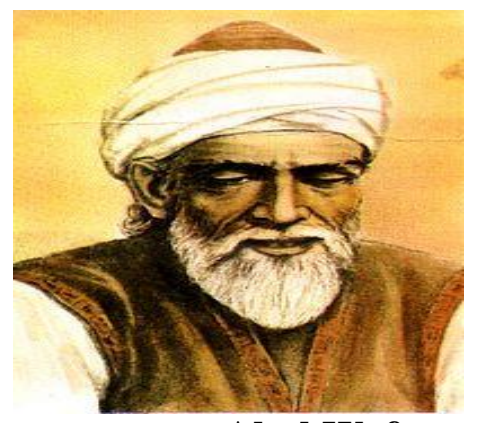

Gambar 6. Abul Wafa

Ilmuwan matematikawan muslim yang terkenal di zaman keemasan islam selain al-Khawarizmi adalah Abul Wafa. Beliau dikenal sebagai ilmuwan yang serba bisa dan terkenal di zamannya. Abul Wafa lahir di Buzjan, Khurasan (Iran) pada tanggal 10 juni tahun 940 M/328 H. Abul Wafa tumbuh besar di era bangkitnya sebuah dinasti Islam baru yang berkuasa di wilayah Iran, dinasti yang bernama Buwaih itu berkuasa di wilayah Persia - Iran dan Irak pada tahun 945 - 1055 M. Abul Wafa salah satu ilmuwan yang namanya diabadikan kawah bulan dengan tujuan mengabadikan dan menghormati pengabdian dan dedikasinya dalam mengembangkan astronomi.

Abul Wafa dikenal sebagai peletak dasar rumus-rumus trigonometri. Abul Wafa mengembangkan ilmu trigonometri dan 
geometri bola serta penemu table sinus dan tangen, juga penemu variasi dalam gerakan bulan. Abul wafa memberikan kontribusi terhadap pemecahan soal-soal geometri dengan menggunakan kompas, konstruksi ekuivalen untuk semua bidang, polyhedral umum, kontruksi hexagon setengah sisi dari segitiga sama kaki, kontruksi parabola dari titik dan solusi geometri bagi persamaan.

Kontruksi bangunan trigonometri versi Abul Wafa hingga kini diakui sangat besar manfaatnya. Dia adalah orang pertama yang menunjukkan adanya "Teori Relatif Segitiga Parabola". Selain itu, dia juga mengembangkan metode baru tentang konstruksi segi empat serta perbaikan nilai sinus 30 dengan memakai delapan desimal. Abul Wafa pun mengembangkan hubungan sinus dan formula " $2 \sin 2(\mathrm{a} / 2)-1-\cos$ a dan juga $\sin a=2 \sin (a / 2) \cos (a / 2) "$ di samping itu, Abul Wafa membuat studi khusus menyangkut teori tangen dan tabel perhitungan tangen. Dia yang pertama kali memperkenalkan secan dan cosecant. Dia berhasil mengetahui relasi antara garis-garis trigonometri yang berguna untuk memetakannya serta meletakkan dasar bagi studi lanjut "teori conic" (Hermanjoyo, 2015).

Secara khusus, Abul Wafa berhasil menyusun rumus yang menjadi identitas trigonometri. Yaitu sebagai berikut:

$\operatorname{Sin}(a+b)=\sin (a) \cos (b)+\cos (a) \sin (b)$

$\operatorname{Cos}(2 a)=1-2 \sin ^{2}(a)$

$\operatorname{Sin}(2 a)=2 \sin (a) \cos (a)$

Selain itu, Abul Wafa pun berhasil membentuk rumus trigonometri untuk parabola yaitu sebagai berikut:

$$
x^{4}=a \text { dan } x^{4}+a x^{3}=b
$$

\section{Al-Tusi, Muhamad Ibn Muhamad Ibn Al-Hasan (juga dikenal sebagai Nasir Al-Din) 1201 - 1274)}

Nasil al-Din al -Tusi lahir pada tanggal 18 Februari 1201 M/ 597 h DI Tus, al - Kazimiyyah dengan Baghdad sebuah tempat yang berada di atas sebuah bukit, di samping lembah sungai Kasyaf, dekat ke kota 
Masyad di Timur Laut Persia.Al -Tusi wafat pada 26 Juli 672 h/1272 - 4 M di Kazhmain dekat Baghdad.

Sebelum Omar Khayyam atau Ibn al-Haytham, beberapa matematikawan pada periode waktu Islam sudah mencoba membaut kelima dalil Euclid sebagai sebuah teorema dalam geometri Euclid. Namun, karya Nasir al-Din dalam bidang geometri Euclid pantas mendapatkan apresiasi tersendiri setidaknya karena empat alasan. Pertama, percobaannya menunjukkan sebuah pengetahuan tentang hubungan antara dalil dan jumlah sudut dalam sebuah bidang segiempat. Kedua, ia menyangkal hipotesis untuk sudut-sudut lancip dan tumpul dengan metode kontradiksi. Ketiga, ia merupakan matematikawan terakhir dari periode waktu Islam, selama empat abad merupakan orang yang paling berminat dalam bidang geometri, mengkritik dan memodifikasi karya-karya pendahulunya dan sezaman dengan dalil keparelelan Euclid. Terakhir, di antara semua matematikawan timur, karyanya merupakan satu-satunya yang bisa mencapai ke Barat Latin, dengan demikian secara langsung mempengaruhi karya-karya Wallis, Saccheri dan lainnya (Mohamed, 2004, hal. 216)

Kontribusi al-Tusi dalam bidang geometri yaitu peran sertanya dalam pembuktian postulat kelima dari kelima postulat Euclid. ia juga memberikan sangkalan bahwa postulat kelima dari kelima postulat Euclid bukanlah postulat namun justru sebuah teorema yang perlu pembuktian. Adapun pembuktiannya dilakukan melalui pemberian proposisi beserta dengan pembuktiannya. Sedangkan kontribusi al-Tusi dalam bidang trigonometri yaitu pembuktian aturan sinusnya yang dilakukan melalui penggambaran busur lingkaran (Purwanti, 2007).

Al-Tusi mengembangkan pendekatan baru terhadap penelitian persamaan kubus, suatu pendekatan untuk mencari titik tempat polinomial kubus mencapai nilai maksimumnya. Misal untuk menyelesaikan persamaan $x^{3}+a=b x$, dengan $a$ dan $b$ positif, ia menulis bahwa titik maksimum kurva $y=b x-x^{3}$ ada di $x=\sqrt{\frac{b}{3}}$, dan persamaan tersebut tidak punya solusi, satu solusi, atau dua solusi, tergantung apakah tinggi kurva 
pada titik tersebut kurang dari, sama dengan, atau lebih besar daripada a. Karya-karyanya yang berhasil diselamatkan tidak memberi petunjuk mengenai cara ia menemukan rumus nilai maksimum kurva tersebut. Berbagai konjektur telah dirumuskan untuk mengetahui bagaimana ia menemukan metode ini (Wikipedia, 2019).

\section{SIMPULAN}

Matematika merupakan ilmu logika dan bernalar karena objek matematika yang masih bersifat abstrak. Penerapan dan pemanfaatan matematika di kehidupan sehari-hari tidak terlepas dari pengetahuan dan kemampuan yang telah dipelajari tentang objek-objek matematika seperti fakta, konsep, operasi dan prinsip. Objek-objek matematika ini tidak terlepas dari penemuan-penemuan para ahli matematikawan terdahulu.

Perdaban Islam yang begitu maju di zaman keemasan dikarenakan saat itu pemerintahan dan masyarakat sangat menjunjung tinggi ilmu pengetahuan dan menghargai perbedaan untuk mengembangkan ilmu agar kehidupan bermasyarakat lebih baik. Tidak dapat dipungkiri bahwa peran peradaban Islam dalam perkembangan ilmu pengetahuan di masa lalu sangatlah berpengaruh terhadap kehidupan yang kita jalani sekarang. Masa kejayaan Islam di masa lampau tidak terlepas dari dari kontribusi ilmuwan muslim, termasuk ilmuwan matematika. Perkembangan ilmu matematika berkembang dengan pesatnya di bawah khilafah Islam yang menguasai timur tengah. Khususnya di bawah pemerintahan Harun AlRasyid dan Al Ma'mun.

Literasi matematika merupakan kemampuan yang wajib ada dalam mempelajari matematika. Dengan mempelajari sejarah ilmuwan-ilmuwan penemu konsep-konsep matematika, peserta didik bisa mengembangkan kemampuan literasi matematika dengan mengetahui konsep-konsep matematika yang ditemukan ilmuwan Muhammad ibn Musa alKhawarizmi dengan penemuan konsep aljabar dan penemuan angka nol, Ibn al- Haytham, Abu Ali al-Hasan Ibn al- Hasan menganalisis nilai mutlak, Al- Biruni, Abu Rayhan Muhammad Ibn Ahmad dengan pembuktian Teorema The Broken Chord yaitu berkaitan dengan sudut 
keliling dalam sebuah lingkaran, Al- Khayyami, Ghiyath al- Din Abu'l Fath Umar Ibn Ibrahim yang bergerak dalam bidang matematika yang meliputi teori garis sejajar, teori perbandingan dan proporsi serta aljabar, Abul Wafa Muhammad Ibnu Muhammad Ibnu Yahya Ibnu Ismail al Buzjani dikenal sebagai peletak dasar rumus-rumus trigonometri, dan Al -Tusi, Muhamad Ibn Muhamad Ibn Al-Hasan dalam bidang geometri yaitu peran sertanya dalam pembuktian postulat kelima dari kelima postulat euclid.

Dalam tulisan ini hanya membahas beberapa ilmuwan muslim terkemuka di masa lalu, masih banyak lagi ilmuwan muslim matematika di masa lalu yang menyumbangkan pikiran dan berkontribusi untuk literasi matematika yang kita manfaatkan dan gunakan pada masa sekarang. Agar pembelajaran matematika menjadi bermakna, dalam pembelajaran matematika sangatlah penting seorang pendidik untuk memaparkan dan menceritakan sejarah siapa penemu konsep-konsep matematika dan bagaimana konsep-konsep matematika ditemukan.

\section{DAFTAR PUSTAKA}

Aji, R. H. (2014). Khazanah Sains dan Matematika dalam Islam. Salam, Jurnal Filsafat dan Budaya Hukum. 155-168. Retrieved from journal.uinjkt.ac.id/index.php/salam/article/1534/109

Anwar, N. (2017). Belajar Lebih dari Matematikawan Muslim. Itqan, 8(2), 17-33. Retrieved from

ejurnal.iainlhokseumawe.ac.id/index.php/itqan/article/101/59

Hermanjoyo. (2015). Abul Wafa, Matematikawan Muslim dibalik Trigonometri. Dipetik April 1, 2019, dari Kompasiana: https://www.kompasiana.com/hj_sriyanto/564f9cafad7e61330f1049 21/abul-wafa-matematikawan-muslim-dibalik-trigonometri

Mohamed, M. (2004). Matematikawan Muslim Terkemuka. Jakarta: Salemba Teknika.

Muhtar, F. (2014). Abu Abdullah Ibn Musa Al-Khawarizmi (Pelopor Matematika dalam Islam). Jurnal Beta, 7(2), 82-97. Retrieved from http://jurnalbeta.ac.id/index.php/betaJTM/article/download/6/5 
Murtiningsih, W. (2011). Para Pendekar Matematika dari Yunani Hingga Persia. Yogyakarta: DIVA Press.

PISA. (2013). PISA 2012 Result: What Students Know and Can Do: Students Performance in Mathematics, Reading and Science. (Volume 1). PISA - OECD Publishing.

Purwanti, D. (2007). Pemikiran Muhammad Ibn Muhammad Ibn AlHasan (Al-Tusi) dalam bidang trigonometri. Yogyakarta: UIN Sunan Kalijaga. Retrieved from digilib.uin-suka.ac.id/18031/

Salmina, M. (2016). Kontribusi Omar Khayyam dalam Bidang Matematika. Maju, 7(1), 29-37. Retrieved from visipena.stkipgetsepana.ac.id/home/article/download/117/118

Wikipedia. (2019). Matematikawan Islam abad pertengahan. Ensiklopedia Bebas: http://id.m.wikipedia.org/wiki/Matematika_Islam_abad_pertengaha n. Diakses April 1, 2019 
82 | Putri: Peran dan Kontribusi Ilmuwan Muslim dalam Pembelajaran Matematika 